\title{
Una posible polisemia en la epistemología naturalizada ${ }^{1}$
}

\author{
Leonardo Cárdenas Castañeda ${ }^{2}$
}

\section{Resumen}

En este artículo expongo una posible polisemia que se puede observar entre los defensores del naturalismo científico, pues si bien filósofos como Quine, Dennett y Giere comparten el espíritu original de la epistemología naturalizada bajo la definición que denominaré D1: “el éxito de la epistemología depende de la manera en que se logren reducir o reemplazar sus problemas por la ciencia", el tratamiento que cada uno de estos filósofos ofrece de la epistemología naturalizada se aparta de esta definición primigenia, pues cada quien privilegia ciertos enfoques que no serían aceptables por los demás, ni se acomodan de igual manera a lo que plantea D1. Así que, a pesar de que los tres acepten la tesis de que la nueva epistemología debe excluir el discurso metafísico que ha dominado la epistemología tradicional y sustituirlo por proyectos netamente científicos, el tratamiento que cada uno por separado le da a esta tesis tiene implicaciones que los otros partidarios del naturalismo encontrarían indefendibles.

Palabras clave: epistemología naturalizada, conductismo, ciencias computacionales, cognitivismo.

\section{A possible polysemy in naturalized epistemology}

\begin{abstract}
In this article I present a possible polysemy that can be observed among the defenders of scientific naturalism, for although philosophers such as Quine, Dennett, and Giere share the original spirit of naturalized epistemology under the definition I will call (D1): the success of epistemology depends on how its problems can be reduced or replaced by science, the treatment that each of these philosophers offers of naturalized epistemology departs from this primitive definition, since each one privileges certain approaches that would not be acceptable to others, nor are those approaches adjusted in the same way to what D1 posits. So, although the three accept the thesis that the new epistemology must exclude the metaphysical discourse that has dominated traditional epistemology and substitute it for purely scientific projects, the treatment that each one separately gives to this thesis has implications that other supporters of naturalism would find it indefensible.
\end{abstract}

\footnotetext{
1 Artículo de reflexión derivado del proyecto de investigación realizado en la Universidad de Caldas, titulado Discusiones y problemas en torno a la epistemología naturalizada, avalado por el grupo de investigación Tántalo del Departamento de Filosofía y Letras de la misma universidad. Financiado por la Vicerrectoría de Investigaciones de la Universidad de Caldas entre febrero del 2017 y mayo del 2019.

2 PhD. en Filosofia, profesor del Departamento de Filosofía de la Universidad de Caldas Manizales, Colombia. Email: leonardo. cardenas@ucaldas.edu.co Autor para correspondencia Leonardo Cárdenas Castañeda email:

leonardo.cardenas@ucaldas.edu.co Recibido: 12/04/2019 Aprobado: 11/06/2019
} 
Keywords: naturalized epistemology, behaviorism, computational sciences, cognitivism.

\section{Uma possível polissemia na epistemologia naturalizada}

\section{Resumo}

Neste artigo apresento uma possível polissemia que pode-se observar entre os defensores do naturalismo científico, pois mesmo que filósofos como Quine, Dennett e Giere compartilham o espírito original da epistemologia naturalizada sob a definição que denominarei D1: "o sucesso da epistemologia depende da maneira como consigam-se reduzir ou substituir seus problemas pela ciência", o tratamento que cada um destes filósofos oferece da epistemologia naturalizada fica longe desta definição primigênia, pois cada quem privilegia certos enfoques que não seriam aceitáveis pelos demais, nem se acomodam de igual maneira no que planteia D1. Assim que, a pesar que os três aceitem a tese que a nova epistemologia deve excluir o discurso metafísico que tem dominado a epistemologia tradicional e substituir ele por projetos nitidamente científicos, o tratamento que cada um individualmente dá-lhe nesta tese tem implicações que os outros partidários do naturalismo encontrariam indefensáveis.

Palavras-chave: epistemologia naturalizada, behaviorismo, ciências computacionais, cognitivismo.

\section{INTRODUCCIÓN}

En este artículo pretendo analizar el debate sobre la epistemología naturalizada desde un punto de vista semántico, haciendo énfasis en los enfoques que varios autores han usado para abordar esta discusión. La epistemología naturalizada, tal como se verá en este trabajo, es un concepto polisémico cuyos distintos significados son irreductibles unos a otros, por lo menos en la perspectiva de lo que en la literatura se conoce como naturalismo científico, cuyo planteamiento central sostiene que es necesario eliminar cualquier explicación metafísica para comprender ciertos fenómenos y que conviene acudir a la ciencia empírica para obtener explicaciones correctas. Puntualmente, esta definición canónica puede ser descrita en estos términos (en adelante la llamaré D1): "el éxito de la epistemología depende de la manera en que se logren reducir o reemplazar sus problemas por la ciencia". Desde esta tesis naturalista voy a argumentar que algunos autores que se consideran a sí mismos seguidores de la epistemología naturalizada, se han alejado progresivamente de la noción original y han dado origen a la polisemia mencionada.

Por otra parte, planeo mostrar la forma como Quine (1969/1986) entiende su propuesta de la naturalización de la epistemología. Además, presentaré el punto de vista de Daniel Dennett (2005/2006) quien considera indispensable descartar las explicaciones de la filosofía tradicional, como las que corresponden a la naturaleza de la mente y de sus fenómenos para poder desarrollar una ciencia de la conciencia. Mi propósito en esta parte es recrear la forma como se ha seguido la sugerencia naturalizadora de Quine en la filosofía contemporánea, pues, 
precisamente, Dennett constituye un buen ejemplo de esta práctica. Luego explicaré algunas modificaciones de la concepción naturalista, especialmente la de Ronald Giere (1988/1992) con su teoría cognoscitiva de la ciencia. Para cerrar este ensayo voy a exponer la siguiente crítica: consiste en argumentar que, según mi opinión, a pesar de que todas las variantes de naturalismo que expongo en este texto hacen énfasis en la importancia de la ciencia para resolver problemas epistemológicos tradicionales (naturalismo científico), asumo que no es posible reconciliarlos en una sola noción, dadas las implicaciones filosóficas que se derivan de cada una. Es aquí donde entiendo que el enfoque original de Quine sobre el naturalismo se diluye y abre el camino para una variedad de nociones sobre la epistemología naturalizada.

\section{La propuesta naturalista de Quine $^{3}$}

En varias partes de la obra de Quine (1969/1986) y (1995/1998) principalmente, podemos notar su aversión por lo que él llama la "filosofía primera" que, en general, abarca un conjunto de temas que tradicionalmente han intrigado a muchos filósofos en sus reflexiones en torno a los problemas clásicos de la teoría del conocimiento, como la justificación de nuestras creencias en la experiencia; el debate sobre el escepticismo o el problema de la inducción, solo por mencionar algunos. Los problemas y soluciones de la filosofía tradicional quedan mejor comprendidos, según Quine, si involucramos en ellos las herramientas de la ciencia empírica. Así que mi punto de vista es que la definición de Quine de la epistemología naturalizada se puede resumir mediante este eslogan (al que me seguiré refiriendo como D2): "el éxito de la epistemología depende de la manera en que se logren reemplazar sus problemas, exclusivamente, por la psicología conductista".

Obviamente, este punto de vista está respaldado por pasajes del siguiente tenor. Dice Quine en Epistemología naturalizada:

La vieja epistemología aspiraba a contener, en un sentido, a la ciencia natural; la construiría, de alguna manera, a partir de datos sensibles. La epistemología en este nuevo planteamiento está, por el contrario, contenida en la ciencia natural, como un capítulo de la psicología (1969/1986, p. 110).

En este pasaje, aparte de mostrar una actitud hostil hacia la manera tradicional en que la epistemología habitualmente aborda algunos problemas de la filosofía (por considerar que sus bases teóricas son poco firmes), Quine enfatiza en dos aspectos que son fundamentales para hacer comprensible el proyecto naturalista: el punto que concierne al lenguaje observacional y la entronización de la psicología como la ciencia que llevará a feliz término los antiguos asuntos aparentemente irresolubles de la epistemología, con una orientación a priori.

Según Quine el lenguaje observacional es el instrumento primario del que nos valemos para hacer emisiones significativas, y funciona tanto para los niños como para los hombres de ciencia. Es decir, la observación directa,

3 Una primera versión de la epistemología naturalizada de Quine la presenté en el número 23 de esta misma revista en el año 2013. El artículo se titula: "La epistemología naturalizada de Quine $v s$. La indeterminación de la traducción. Un enfoque estructuralista". 
y los estímulos sensoriales ${ }^{4}$ cuentan como antesala para poder realizar aseveraciones con algún sentido, fuera de este espacio sería prácticamente impensable elaborar juicios que tuvieran algún valor. Este hecho, según Quine es tan elemental en la naturaleza humana como lo es en algunos animales no humanos el tener la disposición de emitir ciertos sonidos ante la presencia de cualquier rasgo físico o ciertos cambios en el ambiente. Quine lo dice de la siguiente manera: "lo que denomino oraciones observacionales son las oraciones que, en los casos más simples, constituyen las contrapartidas humanas de los cantos de los pájaros y de los gritos de los simios" (Quine, 1995/1998, p. 30).

De ahí, entonces, que para Quine deba existir cierta relación causal entre nuestros rudimentarios pero necesarios estímulos sensoriales y las teorías que dan cuenta del mundo externo. Esa sería la única manera de justificar nuestros conjuntos de creencias y nuestros sistemas de enunciados, ya que están apoyados precisamente en la base empírica. Toda hipótesis científica, si ha de tomarse en serio, requiere de su relación con la observación empírica, pero apelar a otra fuente de validación sería seguir justificando el viejo proceder de la epistemología en la que poca importancia o ninguna se le confería a la ciencia.
Ahora, ¿cuál sería entonces la ciencia que podría despertarnos de las ilusiones promovidas por la filosofía primera? Obviamente Quine está pensando en la psicología conductista como la ciencia en la que el lenguaje observacional, y en general todo el proyecto naturalista, se podrá materializar. La relación entre la psicología conductista de Quine, su noción de estímulos sensoriales y su idea misma de un lenguaje observacional parece pertenecer a ese apartado de la psicología que es el conductismo (como vimos, según Quine, la nueva epistemología, la naturalista, debe ser un capítulo de la psicología). Este es precisamente el vínculo que encuentro entre la epistemología quineana y el conductismo en la versión de John Watson.

Estimulando al sujeto con una campanilla eléctrica o un zumbador, y aumentando o disminuyendo simultáneamente la intensidad de la luz que incide sobre la retina, queda por último condicionado de tal suerte que el estímulo sonoro provocará por sí la dilatación o contracción de la pupila (Watson, La пиеva 51).

El conductismo solamente está dotado del "lenguaje observacional" de estímulo y respuesta y con ello solamente se pueden hacer descripciones igualmente observacionales que han estimulado previamente nuestro sistema sensorial ${ }^{5}$.

\footnotetext{
4 No estoy sugiriendo que la observación directa y los estímulos sensoriales sean equivalentes para Quine. De hecho, Quine afirma que ante una situación similar los estímulos sensoriales de los individuos pueden variar, pero la oración observacional que se construye es parecida, de ahí que la conducta sea semejante. El ejemplo de Quine es que dos individuos ante una oración observacional como "llueve", pueden tener distintos estímulos sensoriales (uno puede sentir caer la lluvia en su cabeza, otro la puede oír a cierta distancia), pero ambos tienen la disposición a resguardarse de ella, bien sea sacando un paraguas o buscando refugio. "Dichos estímulos tenderán sin embargo a parecerse en algún punto, de acuerdo con la apreciación del sujeto; se parecerán, en concreto, en que dan lugar a conductas parecidas" (Quine, La búsqueda 21).

5 La idea en este punto es la siguiente. Tomando la distinción del estructuralismo metateórico entre términos $T$-teóricos (términos de teorías que son propios de ella) y términos $T$-no-teóricos (términos de teorías subsidiarias o anexas), tendríamos que relacionar los términos estímulo y respuesta dentro del vocabulario básico o propio de la teoría, serían estos los $T$-teóricos de la teoría conductista. Más allá de esto no podríamos avanzar, no podría haber $T$-no-teóricos porque no hay teorías previamente disponibles, no hay teorías de base, no habría forma de vincular los términos genuinos de la teoría con otros de teorías diferentes. La importancia de esta taxonomía consiste en que esta da cuenta no solo de las descripciones, sino que también ofrece explicaciones y predicciones dentro de
} 
Reemplazar todos los problemas que hasta ahora han ocupado a la epistemología por una ciencia empírica como la psicología, en especial la conductista, implica el abandono, en últimas de la misma filosofía, siempre y cuando entendamos a esta actividad como un discurso metateórico. O mejor aún, el enfoque reduccionista de Quine sugiere que lo que deberíamos hacer es embarcarnos en la empresa científica y no dar rodeos conceptuales espurios que no llevan a ningún lugar.

Claro, la razón de Quine para otorgar este papel predominante a la psicología conductista radica en que a partir del lenguaje observacional y su conexión con los estímulos sensoriales podemos determinar si las palabras o las oraciones que pronuncia un individuo son o no significativas. Si nuestras retinas son estimuladas por la luz, nos corresponde a nosotros registrar y describir ese fenómeno por medio de nuestro lenguaje con el fin de que tanto teoría y experiencia sean compatibles en todos sus aspectos, pero no podemos esperar a que la construcción de nuestras hipótesis se esfuerce en relacionarse con algún estado de cosas. Tendríamos que empezar analizando cómo es que nuestras terminaciones nerviosas son afectadas por el mundo para poder de allí derivar todo el conjunto de nuestros enunciados y representaciones.

\section{El caso de Dennett}

A lo largo de este trabajo, voy a presentar la siguiente definición de epistemología naturalista de Daniel Dennett (2005/2006) y (1988/2003) (a la que seguiré refiriéndome como D3): "El éxito de la epistemología depende de la manera en que se logren eliminar sus problemas y se sustituyan, solamente, por las ciencias computacionales". En este apartado, seguiré la estrategia y motivación de Dennett para llegar a esta tesis, que a mi entender es la que este filósofo se atribuye.

En la filosofía contemporánea podemos encontrar autores que han tratado de llevar el proyecto naturalista, de acuerdo con los planteamientos de Quine, hasta consecuencias radicales, particularmente movidos por la idea de que la ciencia proporciona información útil para facilitar nuestro conocimiento del mundo. Por ejemplo, Dennett piensa que en la literatura hay obstáculos filosóficos para desarrollar adecuadamente una ciencia de la conciencia, pues muchos autores ${ }^{6}$ se oponen al naturalismo evolutivo y mecanicista que, a su juicio, deben hacer parte de una explicación de lo mental. De hecho, Dennett piensa que, en un caso hipotético, no podríamos distinguir entre un ser humano y una máquina, pues si la máquina se comporta como si tuviera estados mentales conscientes (lenguaje, creencias, etc.) difícilmente podríamos mostrar una

una teoría. Esto es lo que quiero decir cuando afirmo que dentro del conductismo solo podemos realizar descripciones por estar dotado únicamente de términos $T$-teóricos como estímulo y respuesta y carecer de términos de teorías anexas. Para una idea más amplia de la distinción estructuralista que resumo, recomiendo el libro de José Díez y Carlos Ulises Moulines (1999), Fundamentos de la filosofía de la ciencia.

6 Dennett piensa que existe algo así como una "liga reaccionaria" contra la teoría evolutiva y mecanicista de la conciencia, pues se le otorga un papel protagónico, más que a la biología, a la física, tratando de reducir cualquier explicación de la mente a relaciones entre campos electromagnéticos y a fuerzas de atracción y repulsión. Esta tesis, propia de la "liga reaccionaria", según Dennett, es defendida por autores como David Chalmers, Thomas Nagel y Noam Chomsky. 
diferencia sustancial entre el humano y la computadora ${ }^{7}$.

La pretensión de la teoría naturalista de Dennett es que cualquier explicación de la conciencia que involucre descripciones en primera persona (como emociones o sentimientos) debe ser eliminada y reemplazada por descripciones en tercera persona, donde solamente estén involucradas descripciones conductistas de la conciencia. Llegados a este punto, podemos notar que Quine y Dennett tienen una opinión en común, y es que la explicación científica nos permite evitar cualquier justificación metafísica sobre ciertos fenómenos. Por eso la epistemología naturalista (en la versión radical) debe estar en la capacidad de derribar los obstáculos conceptuales de la filosofía. El optimismo de Dennett hacia una ciencia de la conciencia de corte mecanicista está respaldado por pasajes como los siguientes:

Los ordenadores se parecen a la mente como ningún artefacto anterior: controlan procesos para realizar tareas que requieren operaciones de discriminación, inferencia, memoria, cálculo y anticipación; producen conocimiento nuevo y encuentran relaciones (por ejemplo, en la poesía, la astronomía y la matemática) que antes sólo los seres humanos podían tener la esperanza de encontrar (...) La mera existencia de los ordenadores es una prueba cuya influencia ha sido innegable: existen mecanismos (...) responsables de muchas de las competencias que solían atribuirse sólo a la mente (Dennett, 2005/2006, p. 21).
La analogía de Dennett entre la mente humana y las computadoras nos ofrece pragmáticamente una explicación más simple de cómo funciona nuestra mente consciente, pues apela a nociones algorítmicas complicadas para realizar inferencias, predicciones y procesamiento de datos. En cambio, en la filosofía hemos encontrado un montón de teorías como el dualismo mentecuerpo en el que se plantea que debe existir alguna conexión (en opinión de Dennett, inadecuada) entre una entidad corpórea que afecta a una sustancia inmaterial. Así pues, según Dennett, quien no acepte una postura eliminativista con relación a los qualia (el tipo de experiencias subjetivas y privadas que acompañan a ciertas acciones particulares, como la experiencia subjetiva de tener un dolor, o de experimentar la alegría, por ejemplo), o a las descripciones en un lenguaje mentalista (la subjetividad ontológica) por ejemplo, estaría cayendo en la vieja herencia de la filosofía, a saber, el dualismo de propiedades, en el que no es posible traducir las propiedades no físicas del cerebro a sus propiedades físicas, pues se parte de dos sustancias que en teoría son incompatibles, una sustancia material y una sustancia incorpórea. La relación de este punto de vista que asume Dennett con la propuesta naturalista de Quine es notoria por la manera en que Dennett intenta prescindir de cualquier explicación de conceptos de dudosa procedencia (como los qualia) para construir una ciencia de la conciencia. De hecho, el mismo Dennett tiene un ensayo titulado Quinear los qualia (1988/2003), en el que intenta explicar que es irrelevante tratar de ajustar los qualia a alguna rama

\footnotetext{
7 Obviamente, este punto de vista de Dennett es discutible. John Searle (1997/2000), por ejemplo, plantea una situación hipotética, ya bastante conocida en la literatura, "la habitación china". Searle piensa que el computador solo puede hacer combinaciones sintáctico-formales de ciertos algoritmos, pero carece del significado de sus contenidos. En síntesis, según Searle, en contraposición a Dennett, sí podemos establecer criterios objetivos para diferenciar entre una máquina y un ser humano, pues los estados mentales del último involucran una semántica.
} 
de la ciencia cognitiva, pues su existencia es ilusoria. Obviamente, este punto a favor del eliminativismo en el argumento de Dennett es ampliamente discutible, pues para filósofos como John Searle, el eliminativismo de los qualia no implica necesariamente abrazar alguna postura dualista. Para defender esta propuesta, Searle establece una distinción entre la reducción ontológica y la epistemológica. La primera afirma que los estados mentales no son más que estados físicos, la segunda defiende la posibilidad de explicar los rasgos de los estados mentales utilizando el lenguaje de las ciencias empíricas. Puede afirmarse que el dualismo de propiedades rechaza los dos tipos de reducción mientras que Searle acepta un tipo débil de reducción epistemológica en términos neurofisiológicos. Llegar a afirmar que aceptar la eliminación de los qualia, significa abrazar el dualismo, es confundir la subjetividad ontológica de las experiencias conscientes con su objetividad epistemológica. El hecho de que nuestros fenómenos subjetivos que acompañan a nuestras experiencias conscientes dependan de que ellas aparezcan ante los individuos, no implica la imposibilidad de tener un conocimiento objetivo de su naturaleza. Dennett considera entonces que nada le hace más bien a la ciencia cognitiva que eliminar de la explicación de la conciencia a los qualia y al lenguaje mentalista y, como lo decía atrás, para este fin es necesario partir de descripciones en tercera persona, donde lo único que podemos explicar son los aspectos físicos que se pueden advertir intersubjetivamente.

\section{Naturalismo cognitivo y evolucionista}

Al igual que Quine y Dennett, Ronald Giere (1988/1992) es partidario de una concepción naturalista de la epistemología en la que la empresa científica se lleva los mayores elogios, pues Giere sugiere que la nueva epistemología debería abandonar las reflexiones filosóficas y tratar de constituirse en "una ciencia de la ciencia". De hecho, en el prólogo a su libro, La explicación de la ciencia: un acercamiento cognoscitivo, deja ver su claro compromiso con un programa fuerte en epistemología en el que, por un lado, se pueda restringir la posibilidad teórica de la filosofía en función de la ciencia y, por otro, se pueda diferenciar esta nueva perspectiva naturalista de la filosofía de la ciencia del resto de la epistemología tradicional. El siguiente pasaje da cuenta de estos dos planteamientos que expone Giere:

Desde ciertas perspectivas filosóficas tradicionales, la filosofía naturalizada de la ciencia no es en absoluto parte de la filosofía. Si se considera la filosofía de la ciencia como parte de la epistemología, por ejemplo, la empresa predominante ha sido la de mostrar cómo los enunciados del conocimiento científico pueden justificarse de una manera no circular y satisfactoria. El objetivo filosófico, dicho sea, en dos palabras, ha sido el de proporcionar cierto fundamento extracientífico a los asertos científicos. Este proyecto me parece ahora simplemente una versión moderna del proyecto medieval de proporcionar pruebas filosóficas de la existencia de Dios. Tal proyecto podría nombrarse mejor "teología de la ciencia" o "apologética científica" (Giere, 1988/1992, p. 17) ${ }^{8}$. 
Ahora, a pesar de esta caracterización fuerte que Giere hace de la epistemología naturalizada, sería equivocado interpretar el asunto como si la filosofía fuera inútil para la labor científica. Lo que Giere está tratando de decir es que es menester que la filosofía haga parte del propósito científico, es la única manera de emplear provechosamente la labor metateórica que ofrece la filosofía, en la medida en que la teoría es tan importante para explicar los acontecimientos de la ciencia como es tan relevante la ciencia misma para explicar ciertos acontecimientos naturales. En otras palabras, Giere considera que mientras se llega a completar la tarea de naturalizar la epistemología, no nos queda otro camino que seguirle otorgando un estatus especial a la filosofía, como actividad en la que se sugieran razonamientos metateóricos. La filosofía en este caso sería un tránsito obligado, aunque provisional, para el propósito naturalista de Giere. De ahí en parte su distanciamiento de la metafísica tradicional.

La inclinación de Giere hacia el naturalismo hace parte de lo que él denomina "teoría cognoscitiva de la ciencia" que consiste en hacer uso de las herramientas de la ciencia cognitiva para elaborar una explicación científica de una manera amplia. En otras palabras, lo que Giere entiende por "teoría cognoscitiva de la ciencia" no se limita solo a las ciencias computacionales o a la psicología cognitiva, su propuesta incluye a la lógica, la filosofía, la inteligencia artificial, la lingüística, la sociología y la antropología cognitivas. Precisamente, Giere piensa que este punto de vista es amplio y unificacionista porque no descarta a priori ningún área que pueda llegar a ser provechosa para explicar el "fenómeno de la ciencia moderna", como él lo llama. En este orden de ideas, creo que ha llegado el momento de emplear el lema naturalista de Giere (D4): "El éxito de la filosofía depende de la manera en que se logren reemplazar sus problemas por todas las ciencias cognitivas".

Una de las estrategias de las que se vale Giere para defender el naturalismo cognoscitivo, consiste en exponer los defectos que él encuentra en la explicación científica tradicional. Giere piensa que esas fallas se enfocan en el uso del concepto de "racionalidad categórica" de la epistemología tradicional. Según Giere, la racionalidad puede ser descrita de dos sentidos, racionalidad categórica y racionalidad hipotética. El primero es el que se atribuye a Aristóteles, quien le adjudica al hombre la propiedad esencial de ser un animal racional, es decir, la definición de hombre parte del fundamento sustancial de esta propiedad. El segundo sentido de racionalidad es de carácter pragmático y se distingue por la manera en la que somos capaces de actuar de una manera eficaz para lograr ciertas metas, esta es la racionalidad hipotética o instrumental, que según Giere es compatible con su teoría cognoscitiva de la ciencia, pues lo que hace el científico cognoscitivo es evaluar instrumentalmente la manera como el científico mismo realiza determinados juicios, dependiendo de sus propios intereses individuales y cómo ellos son satisfechos. Esto es, según Giere, ver el proceso de toma de decisiones de los científicos de una manera naturalista, apegada a sus expectativas sociales y personales. Así, Giere piensa que las preguntas adecuadas para esta tarea son del siguiente corte: “¿qué estrategias usan

por ejemplo, diseñó un criterio de demarcación no justificacionista entre lo que es ciencia y lo que es metafísica, y nada tiene que ver con algún programa naturalista. 
los sujetos para alcanzar sus metas? ¿Se desempeñan tan bien en la consecución de sus metas como podrían hacerlo dadas las circunstancias?" (1988/1992, p. 27).

Ahora bien, Giere piensa que, precisamente, la antigua tradición epistemológica estuvo dominada por la concepción categórica de la racionalidad, pues parte de su definición provenía de la idea biológica de que a las especies hay que comprenderlas desde sus cualidades esenciales. Ese tipo de dificultades se superan, según Giere, con la epistemología evolucionista a la que él se adhiere, porque con Darwin nos encontramos con la teoría de que las supuestas propiedades esenciales de los individuos es falsa, en biología se ha descubierto que hay variaciones de cualidades en los individuos, pero nunca la biología nos enseñó que hubiera, algo así, como "la clase natural" que identificara a los organismos.

De esta manera, según Giere, el trasfondo que permitiría a la teoría cognoscitiva de la ciencia ser desarrollada correctamente es la teoría de la evolución de Darwin. Giere piensa que el evolucionismo muestra no solo la supervivencia biológica del más fuerte, su adaptación al medio y su capacidad para dejar descendencia; también considera que el evolucionismo indica que el desarrollo científico se da en términos de su capacidad para dar cuenta de lo que sucede en el ambiente y en su forma de ser compatible con un estado de cosas ${ }^{9}$. En otras palabras, la teoría darwinista de la evolución es una señal de que las teorías científicas son exitosas en la medida en que se asemejan a los hechos, por eso esta teoría es mejor en poder explicativo frente a otras alternativas. Giere denomina a esta tesis "realismo naturalista", es la ciencia cognitiva como actividad humana, es un fenómeno natural que cada vez demuestra tener éxito empírico ${ }^{10}$.

\section{La polisemia}

Recordemos que el naturalismo que estoy examinando en este artículo es el de corte científico, así que la polisemia que pretendo mostrar se ciñe a aquellos autores que proclaman la consigna que se propuso al inicio del presente texto: (D1) "el éxito de la epistemología depende de la manera en que se logren reducir o reemplazar sus problemas por la ciencia". Precisamente, creo que la polisemia radica en que tanto Quine, Dennett y Giere entienden la locución ciencia natural de una manera diferente, si tomamos en cuenta las distintas implicaciones de sus respectivas formulaciones.

Como vimos, lastesis de Quiney Dennett sobre el naturalismo reduccionista parte de la idea según la cual la filosofía tradicional ha sido insuficiente para explicar el funcionamiento de ciertos fenómenos naturales, como la conciencia. Así que la alternativa más adecuada es tomar el toro por los cuernos y ponernos a resolver los problemas filosóficos desde dentro de la misma ciencia, pues de lo contrario corremos el riesgo de seguir

\footnotetext{
9 No olvidemos el realismo constructivo de Giere, pues la relación de las teorías (en este caso el evolucionismo) y el mundo se da en términos de semejanza, no de verdad

10 Esta posición de Giere hace parte de un realismo más general, conocido como realismo científico, en el sentido en que las teorías científicas constituyen la mejor herramienta para obtener un conocimiento del mundo, de manera parcial o aproximada. De hecho, el mismo Giere se adhiere al realismo científico, pero no a la manera como lo comprende la concepción heredada de las teorías científicas, que parte de la definición de teoría como un conjunto de enunciados (Carnap, Popper, Bunge). La postura realista de Giere se puede encontrar de manera más detallada en el capítulo IV de este libro y en (2005) Scientific Realism: Old and New Problems.
} 
ladrándole a la luna y cayendo al mismo punto de siempre, es decir, reescribiendo los mismos argumentos de la filosofía clásica. De hecho, como mencioné atrás, más que reduccionistas, los puntos de vista de Quine y Dennett son eliminativistas con respecto a la filosofía. Sin embargo, creo que la idea de reducir la filosofía a la ciencia o eliminarla definitivamente, no le hace justicia al importe de este punto de vista de la epistemología naturalista, pues si lo que tienen en mente Quine y Dennett cuando dicen que la nueva epistemología evitará los desvaríos teóricos de la teoría del conocimiento tradicional (como las explicaciones metafísicas y el lenguaje mentalista), reemplazándola por la investigación científica, entonces no le atinan al blanco, como veremos enseguida. En primer lugar, el mismo empirismo tan radical que defiende Quine lo lleva a aceptar el principio verificacionista de los positivistas, pero de una manera más holista, es decir, no solo se ajusta a sistemas semánticos, sino también al conocimiento científico, porque como lo señala Guerrero Pino (2011), obliga a la ciencia a hacer modificaciones en el interior de una teoría, ante "experiencias refutadoras". En ese sentido, Quine se parece más a sus colegas positivistas de lo que él mismo cree. De hecho, filósofos actuales como Alberto Cordero sugieren que Quine es, incluso, más empirista que los mismos positivistas lógicos, lo que lo hace ver como un filósofo con una actitud conservadora fuerte y no tan revolucionaria. Cordero dice que:

Quine es un naturalista que piensa que la epistemología tiene un futuro solamente como ciencia auto-aplicada, pero es también un filósofo de la vieja guardia que cree que las meras posibilidades lógicas tienen importancia epistemológica. De manera menos explícita, Quine es, además, un empirista acérrimo (Cordero, 1997, p. 189).
Por otra parte, Quine pretende que su proyecto de refundar la epistemología se base en la experimentación científica, de ahí su respaldo especial a la psicología conductista, la cual se ajusta a su ideal naturalista de no reificar ni las nociones intensionales, ni el lenguaje mentalista, ni el "lodazal intensional" de las modalidades.

Con base en este panorama, la epistemología naturalista de Quine en los términos en que la presenté atrás (D2): "el éxito de la epistemología depende de la manera en que se logren reemplazar sus problemas, exclusivamente, por la psicología conductista". Precisamente, en el sentido, según Quine, en que no solo los problemas de la epistemología tradicional se comprenden mejor si incluimos los servicios de la ciencia empírica, sino que esa ciencia empírica para él no es otra que la psicología conductista, porque da cuenta tanto de los estímulos sensoriales como del lenguaje observacional que el mismo Quine privilegia. En lo que sigue, argumentaré que los puntos de vista de Dennett y Giere también se pueden reconstruir, de manera tal, que se alejan del significado original de la tesis del naturalismo.

Daniel Dennett, por ejemplo, intenta llevar el proyecto quineano a sus últimas consecuencias, en la medida en que también busca desembarazarse de los viejos "mitos" filosóficos del pasado. Como se mostró, tal vez una de las partes de la epistemología de Dennett que más se acerca a Quine es la idea misma de quinear los qualia, es decir, eliminar aquellos tipos de experiencias subjetivas y privadas como el dolor o la alegría. Según Dennett, esto es importante para la teoría cognoscitiva de la ciencia que él propone, pues privilegia los aspectos 
físicos y la descripción en tercera persona del fenómeno de la conciencia. Por estas mismas razones, Dennett parece comprometerse con el conductismo extremista de Quine.

No obstante, creo que la fidelidad de Dennett a Quine se ve comprometida por su dependencia de la lógica modal. En $L a$ evolución de la libertad, Dennett se apoya en la semántica de los mundos posibles para argumentar a favor de la compatibilidad de la libertad y el determinismo. Básicamente, el argumento de Dennett es que, si hacemos un uso adecuado de las modalidades, podemos mostrar que la libertad debe consistir en lo fisicamente posible y en lo lógicamente posible, es decir, la manera en que debemos entender las modalidades es desde el punto de vista epistémico y no desde el ontológico. Según Dennett, como nuestro conocimiento del mundo es limitado, tenemos una gama de posibilidades para poder decidir sobre nuestro futuro en "un mundo subjetivamente abierto" y aun "los mundos deterministas pueden dar cabida cómodamente a posibilidades en el sentido más amplio e interesante del término"(Dennett 2003/2004, 104) $)^{11}$. Para ilustrar lo anterior, Dennett afirma lo siguiente: "Cada usuario finito de información tiene un horizonte epistémico; no lo sabe todo del mundo que habita, y esta ignorancia insuperable garantiza que tenga un futuro subjetivamente abierto" (Dennett, 2003/2004, pp. 113-114).

Lo que quiero rescatar de este enfoque es que, si empleamos las modalidades desde el punto de vista epistémico o de dicto, no las estamos interpretando como si fueran parte del mobiliario del mundo. Por eso Quine elimina las modalidades, ya que chocan con la manera extensionalista del discurso que él recomienda. Obviamente, Quine piensa de esta manera porque su actitud hacia las modalidades es que son de re, o sea, son asumidas ontológicamente. Dennett, por su parte, está aceptando que las modalidades hay que comprenderlas como parte de un conjunto de predisposiciones con que contamos para relacionarnos con el mundo. Por esta misma razón, Dennett afirma lo siguiente:

Y son estos problemas - los problemas que surgen cuando saltamos del nivel básico de los átomos y el espacio a categorías ontológicas superiores- los que alimentaron el escepticismo de Quine acerca de la posibilidad de hablar con sentido sobre la posibilidad y la necesidad (2003/2004, p. 85).

El naturalismo de Dennett debemos comprenderlo de la forma en que las modalidades son compatibles con su ideal de la neurociencia cognitiva y en general, con la inteligencia artificial.

Entonces, si Dennett es coherente con su ideal científico, su proyecto de naturalización epistemológica no puede ser el mismo que el que Quine promueve. Si Dennett asume que la neurociencia tiene que emplear nociones modales (en este caso la modalidad de posibilidad), como cualquier otra ciencia, distinta al conductismo radical de Watson y Quine, la redefinición que sugiero de su propuesta naturalista puede concluirse en los términos que exponía antes (D3): "el éxito de la epistemología depende de la manera en que se logren eliminar sus problemas y se sustituyan, solamente, por las ciencias

11 Algunos filósofos, como Antonio Guerrero del Amo (2007), han mencionado que, dado que Dennett les abre paso a las modalidades en su proyecto epistemológico, estaría flaqueando en su objetivo de eliminar la metafísica. 
computacionales"12. El punto es que con la puesta en juego de las modalidades por parte de Dennett, su enfoque naturalista toma distancia del naturalismo de Quine.

Por último, en lo que concierne a Giere, a pesar de que su naturalismo parte de la misma confianza en la ciencia que le otorgan Quine y Dennett, y en el descrédito a la epistemología tradicional (que también comparten estos autores), pienso que hay aspectos importantes que lo distancian de ellos y por eso creo que, en su caso, su lema epistemológico tiene un significado totalmente distinto. Quisiera mencionar tres aspectos que diferencian la epistemología naturalizada de Giere de la propuesta quineana: su rechazo al conductismo, su ideal unificacionista de la ciencia y su adhesión al realismo modal (esta última diferencia también la podemos extender a Dennett).

Según Giere, lo que le impide acompañar al conductismo es que en esta teoría es necesario hacer énfasis en la descripción de la tercera persona; en registrar únicamente la conducta observable y, por tal motivo, cualquier pronunciamiento del individuo sobre su mundo subjetivo o su marco representacional interno es irrelevante. Giere se aleja de esta postura, pues como vimos, para él son importantes las representaciones internas que el individuo o el científico posee, recordemos que para Giere las representaciones "son mapas internos del mundo externo". El mismo Giere marca su distancia del conductismo de la siguiente forma:

La idea central de las ciencias cognoscitivas es probablemente que los hombres (y los animales) producen representaciones internas de su ambiente (al igual que de sí mismos). Es el apelar a representaciones internas, mentales, por ejemplo, lo que distingue fundamentalmente a la psicología cognoscitiva del conductismo. Dependiendo del campo particular de las ciencias cognoscitivas, hablamos de cosas como los "esquemas", "mapas cognoscitivos", "modelos mentales" o "marcos" (Giere, 1988/1992, p. 26).

Justamente, el reduccionismo de Quine se basa, como se ha dicho, en la solidez que encuentra en las observaciones empíricas y en la imposibilidad de individuar el discurso intensional y modal, ahí su apego al conductismo. Giere, por su parte, apela a una teoría cognoscitiva de la ciencia con el agregado de la unificación. Es decir, Giere pretende ofrecer una explicación científica de los fenómenos naturales, a partir de la propia ciencia, excluyendo a la filosofía, pero sin restringirse a una ciencia en particular, como lo hace de manera más explícita Quine. Para la ciencia moderna puede resultar muy útil el uso de otras ciencias como la lingüística, la inteligencia artificial, la psicología, la sociología y la antropología y no las podemos desechar a priori.

En cuanto a las modalidades, Quine y Giere aceptan que estas se interpretan como si fueran de re, de manera ontológica y no desde un enfoque epistémico, lingüístico o de dicto, como lo hace Dennett. Sin embargo, la diferencia es que mientras Quine las rechaza porque no encajan en el conductismo extensionalista, Giere las acepta como un complemento de los enseres que pueblan el mundo.

12 Obviamente, no estoy sugiriendo que la diferencia entre el conductismo y la neurociencia se base solamente en la forma en que se emplean las modalidades. Es más, la diferencia que aquí me interesa rescatar es de índole epistémica. 
Una de las implicaciones del realismo constructivo de Giere es la aceptación de nociones modales como la necesidad, la posibilidad y la probabilidad en sistemas reales. Él piensa que una manera adecuada de que los modelos representen algún aspecto del mundo es considerar la existencia de su "estructura modal" en casos donde la "tendencia causal" sea lo suficientemente fuerte.

\section{Conclusiones}

Llegados a este punto y tomando como referencia las diferencias de Giere con respecto a Quine y Dennett, podemos recordar la versión de Giere sobre la epistemología naturalizada que enunciábamos arriba (D4): "el éxito de la filosofía depende de la manera en que se logren reemplazar sus problemas por todas las ciencias cognitivas".

Si bien las tres versiones comparten en la definición inicial(D1) una predilección por la ciencia, se me podría objetar que el problema es solo de enfoques, de las particularidades de cada autor para entender el naturalismo, que todos se muestran complacidos con la idea de la superación de la metafísica a través de la ciencia empírica. Sin embargo, pienso que este rasgo no es suficiente para sostener que se está hablando de una epistemología naturalizada de manera uniforme. Otra cosa sería que, por ejemplo, la postura quineana, caracterizada en (D2), admitiera o dejara la puerta abierta para otras ciencias cognitivas como lo hace Giere en su (D4), pero el conductismo con el que él se compromete solamente le da lugar a la psicología (conductista), ni siquiera a la psicología cognitiva, que trata de explicar ciertos procesos cognitivos internos, como la mente. Tampoco, la ciencia computacional como se describía en (D3) podría caber en el enfoque de Quine, dado que una ciencia con esta orientación apela a una lógica modal o probabilística, cosa que el mismo Quine también rechaza. Tal vez, la única postura que puede ser compatible con las demás es la definición (D4) de Giere, por el hecho de que es más pluralista u holista (por eso es unificada), reúne todas las ciencias cognitivas. Pero el rechazo de Giere hacia el conductismo, hace que la posibilidad de articular la definición (D2) a la (D4) sea mínima. Ahora bien, la única dificultad que, a mi modo de ver, resultaría para relacionar (D3) y (D4) pasa por el tratamiento que Dennett y Giere hacen de la lógica modal y por el papel privilegiado que el primero otorga a las descripciones de tercera persona, lo cual suprimiría el punto de vista del segundo sobre las representaciones internas y mentales (en primera persona) de los seres humanos. El resultado final de estas tres posiciones sobre la epistemología naturalizada, y es lo que he querido demostrar, es que cuando se toman en cuenta las implicaciones filosóficas de cada una, entonces se separan de la comunión inicial a favor de la ciencia. Así pues, estos autores que se estiman a sí mismos seguidores de la epistemología naturalizada, se han alejado progresivamente de la noción original y el enfoque de Quine sobre el naturalismo se diluye, abriendo el camino para una variedad de nociones sobre la epistemología naturalizada.

\section{Referencias}

Cárdenas, L. (2013). La epistemología naturalizada de Quine vs. La indeterminación de la traducción. Un 
enfoque estructuralista. Discusiones Filosóficas, 14(23), 179-194.

Cordero, A. (1997). Las ideas evolucionistas y el naturalismo contemporáneo. En S. Martínez y L. Olivé (Comps.), Epistemología evolucionista (pp. 185220). Ciudad de México: Paidós.

Dennett, D. (2006). Dulces sueños: obstáculos filosóficos para una ciencia de la conciencia. Buenos Aires: Katz.

Dennett, D. (1988/2003). Quinear los qualia. En M. Ezcurdia y O. Hansberg (Comps.), La naturaleza de la experiencia (Vol. 1) (pp. 213-262). Ciudad de México: Universidad Nacional Autónoma de México.

Dennett, D. (2004). La evolución de la libertad. Barcelona: Paidós.

Diéguez, A. (1998). Realismo científico: una introducción al debate actual en la filosofía de la ciencia. Málaga: Universidad de Málaga.

Díez, J. y Moulines, C. (1999). Fundamentos de filosofía de la ciencia. Barcelona:Ariel.

Giere, R. (1992). La explicación de la ciencia: un acercamiento cognitivo. Ciudad de México: Consejo Nacional de Ciencia y Tecnología.

Giere, R. (2005). Scientific Realism: Old and New Problems. Erkenntnis, 63(2), 149-165.

Guerrero del Amo, J. A. (2007). Las dificultades del compatibilismo de
Dennett. Thémata. Revista de Filosofía, (39), 97-103.

Guerrero Pino, G. (2011). Un esbozo del sistema epistemológico de Quine. Discusiones Filosóficas, 12(19), 155-180.

Quine, W. V. O (1969/1986). Naturalización de la epistemología. En La Relatividad Ontológica y Otros Ensayos (pp. 93-119). Madrid: Tecnos.

Quine, W. V. O (1998). Del estímulo a la ciencia. Barcelona: Ariel.

Quine, W. V. O (1992). La búsqueda de la verdad. Barcelona: Crítica.

Searle, J. (2000). El misterio de la conciencia. Barcelona: Paidós.

Watson, J. (1984). La nueva y la vieja psicología en oposición. Buenos Aires: Paidós 